\title{
Effects of Süßstofftabletten on Some Physiological Parameters in Male Albino Rats and The Curative Effects of Vitamin E
}

\author{
Eman G.E. Helal ${ }^{1}$, Mohamed A. Abdelaziz ${ }^{2}$, Mariam S. El-Gamal ${ }^{1}$
}

${ }^{1}$ Department of Zoology, Faculty of Science (Girls), Al-Azhar University,

${ }^{2}$ Medical Physiology, Faculty of Medicine, Al-Azhar University

* Corresponding author: Eman Helal, email: emanhelal@ hotmail.com, mobile:00201001025364, orcid.org/0000-0003-0527-7028

\begin{abstract}
Background: Süßstofftabletten is an artificial sweetener, which is mainly composed of cyclamate and saccharin. Aim of the work: clarification of Süßstofftabletten effects and the amelioration effect of vitamin $E$ in male albino rats. Materials and methods: thirty male albino rats weighing from 100 to $120 \mathrm{gm}$. The period of the experiment was 30 days. The animals were divided into three groups; group 1: control, group 2: rats received Süßstofftabletten (1 tablet $/ 25 \mathrm{~kg}$ b.w./day) and group 3: rats received Süßstofftabletten (1tablet $/ 25 \mathrm{~kg}$ b.w./day) + vitamin E (6 mg/kg b.w./day). The following parameters were measured: serum glucose, ASAT, ALAT, serum creatinine, serum urea, protein and lipid profiles and hormonal levels (insulin, testosterone, serum T3 and serum T4).

Results: there were many disturbances that occurred in the previous parameters, and vitamin E ameliorated most of these hazardous effects.

Conclusion: the assertions that artificial sweeteners are safe and healthy in use by consumers are false. Natural sweeteners whose benefits are important and necessary to our bodies must be used instead of artificial sweeteners. Also vitamin $E$ is very important in our daily diet as it fights many damages that encounter us.
\end{abstract}

Keywords: Süßstofftabletten, cyclamate, saccharin, vitamin E, ASAT, ALAT, T3, T4, testosterone, insulin.

\section{INTRODUCTION}

Synthetic sweetener is a food additive that simulates the effect of sugar on taste. Therefore, they are called sugar substitutes. Consumers often choose those foods that are made up of low-calorie sweeteners because they want a taste of sweetness without adding calories. The dietary option is that this product may be useful in managing obesity or diabetes ${ }^{\mathbf{1})}$.

Cyclamate is derived from N-cyclo-hexylsulfamic acid (CHS) and is widely used as a nonthermal industrial solution in food and beverage as well as in the pharmaceutical industry. It is odorless and soluble in water, alcohol, propylene glycol, aspartame and saccharin. Thus, may be submitted to variations in temperature (2). Cyclamate is 30 times sweeter than sucrose and it has a synergistic sweetening effect when combined with saccharin. Cyclamate is absorbed partially from the intestine, and a variable amount is converted to cyclohexylamine by microorganisms in the large bowel. After cyclamate administration in some nonhuman mammals, $N$-hydroxy cyclohexylamine was found in urine. Cyclohexanol and cyclohexane have also been reported as trace metabolites of cyclamate in rats, rabbits, guinea pigs, monkeys, and humans, probably arising from metabolism of cyclohexylamine (3). In 1970, Price et al. (4) reported an increased incidence of bladder tumors in rats dosed with a mixture of sodium cyclamate and sodium saccharin that led to a ban on the use of cyclamate as an artificial sweetener in a number of countries, including the United Kingdom and the United States.

Saccharin is an artificial sweetener that has been widely accepted as a sugar substitute. It is 300 to 500 times sweeter than sucrose, but it has a slightly bitter aftertaste. It is known under the E number E954.
It is the most important and widely used sweetener, as it goes directly through the human digestive system without being digested ${ }^{(5)}$. Saccharin is a very stable compound with respect to heat and time so that it can be used in hot beverages and in food processing that involves application of high temperature. There are different forms of saccharin including sodium saccharin, calcium saccharin, potassium saccharin and acid saccharin. Sodium saccharin is more often used as it is more palatable ${ }^{(\boldsymbol{\sigma})}$. Although, saccharin has been extensively investigated, most of research has produced conflicting reports. Saccharin is widely accepted as a sugar substitute, but consumption of saccharin should be in adherent to the FDA recommended approved daily limit. Furthermore, consumers should be aware of its risks and benefits, as several reports have shown association with bladder cancer, as well as incidents of other cancers ${ }^{(5)}$.

Süßstofftabletten is made and used in Germany. It contains sodium cyclamate and sodium saccharin.

Vitamins are ideal antioxidants to increase tissue protection from oxidative stress due to their easy, effective and safe dietary administration in a large range of concentrations. One of the most important vitamins for the body is vitamin E. In nature, vitamin $\mathrm{E}$ comprises eight natural fat-soluble compounds, including 4 tocopherols [d-alpha-, d-beta-, d-gammaand d-delta tocopherol] and 4 tocotrienols [d-alpha-, dbeta-, d-gamma- and d-delta-tocotrienol] ${ }^{(7)}$. Vitamin $\mathrm{E}$ is an important antioxidant factor. It is known to possess various physiological functions. A major contributor to non-enzymatic protection against lipid peroxidation is vitamin E, a known free radical scavenger. Vitamin $\mathrm{E}$ as a lipid soluble, chain-breaking antioxidant plays a 
major protective role against oxidative stress and prevents the production of lipid peroxides by scavenging free radicals in biological membranes ${ }^{\left({ }^{(8)}\right.}$. Since the discovery of vitamin E in 1922 when it was first described as an anti-sterility agent, many scientists and physicians have sought to elucidate its biochemistry, health benefits and clinical applications $^{(\mathbf{( 9 )}}$.

The questions arise here:

1- Does the use of both sweeteners sodium cyclamate and sodium saccharin are more danger on human health than the use of only one of them?

2- Can vitamin E ameliorate the effects of Süßstofftabletten?

So, this study aimed to clarify the dual effects of Süßstofftabletten and the protective role of vitamin E.

\section{MATERIALS AND METHODS}

Süßstofftabletten: consists of $\mathbf{4 0} \mathbf{~ m g}$ of sodium cyclamate, acidity regulator sodium bicarbonate, acidifier L (+) - tartaric acid and $4 \mathrm{mg}$ of sodium saccharin. It is manufactured in Germany by REWE Handelsgruppe GmbH, D-50603 Köln.

Vitamin E: manufactured in Alexandria by PHARCO pharmaceuticals.

Thirty male albino rats (weighing from 100 to 120 g) were used in this study. Animals were housed in stainless steel cages, fed on rat chow and offered water ad libitum. The animals were divided into three equal groups (10 rats each) as follows: The first group: the control untreated group, the second group: rats received orally Süßstofftabletten (1 tablet $/ 25 \mathrm{~kg}$ b.w./day), each tablet contains $40 \mathrm{mg}$ of sodium cyclamate and $4 \mathrm{mg}$ of sodium saccharin and the third group: rats received orally Süßstofftabletten (1 tablet/25kg b.w. /day) and vitamin E (6 mg/kg b.w.). Body weights were recorded at the beginning and at the end of the experiment. After 30 days, animals were weighed and then decapitated.

Blood samples were collected for biochemical parameters. Blood samples were centrifuged for $15 \mathrm{~min}$. at $5000 \mathrm{rpm}$ and supernatant sera were separated for analysis.

\section{Biochemical Examination}

In the present study, total protein (TP) and albumin concentrations were estimated. Then, serum globulin concentrations were calculated according to the formula:

Globulin $(\mathrm{g} / \mathrm{dl})=$ total protein $(\mathrm{g} / \mathrm{dl})-$ albumin $(\mathrm{g} / \mathrm{dl})$ Aspartate aminotransferase (ASAT), alanine aminotransferase (ALAT) activities, creatinine, urea, glucose concentrations as well as lipid profile including total cholesterol, triglycerides and high-density lipoprotein cholesterol (HDL-C) were also determined. All parameters were estimated using BioMerieux SA kits, France.

The ratio of serum albumin/globulin was determined. However, ratios of TC/HDL (risk factor 1) and LDL/HDL (risk factor 2) were also calculated after calculation of serum LDL-C (low-density lipoprotein cholesterol) and VLDL (very low-density lipoprotein cholesterol) using the Friedwald's ${ }^{(\mathbf{1 0})}$ and Norbert ${ }^{(11)}$ formulas, respectively as following:

Friedewald's ${ }^{(10)}$ equation: LDL $(\mathrm{mg} / \mathrm{dl})=\mathrm{TC}-\{\mathrm{HDL}$ $+[$ TG/5] $]$.

Norbert ${ }^{(11)}$ equation: VLDL $=$ TG/5

Insulin was determined using ELISA kit (101250-01, Mercodia AB, Uppsala, Sweden). The HOMA-2 IR index (Homeostatic Model Assessment of Insulin Resistance) was calculated by a free online calculator (HOMA Calculator, Version 2.2.3, Diabetes Trail Unit, The University of Oxford, Oxford, UK).

HOMA-IR $=\frac{[(\text { Glycaemia }(\mathrm{mg} / \mathrm{dl}) / 18.2) \times \operatorname{Insulin}(\mathrm{mU} / \mathrm{ml})]}{22.517}$ (12)

Testosterone, T3 and T4 were estimated by using VIDAS $^{\circledR}$ kits, which are automated quantitative tests.

Ethical approval:

This study was conducted in accordance with ethical procedures and policies approved by Animal Care and Use Committee of Faculty of science, Al-Azhar University, Cairo, Egypt.

The study was approved by the Ethics Board of Al-Azhar University.

\section{Statistical analysis}

The results were expressed as mean $\pm \mathrm{SE}$ of the mean. Data were analyzed by using t-test and were performed using the Statistical Package (SPSS) program, version 20. The Bonferroni test was used as a method to compare significance between groups.

\section{RESULTS}

As regards body weight, highly significant decrease $(\mathrm{p}<0.01)$ was noticed in the percentage of body weight change in Süßstofftabletten group, while vitamin E-treated group recorded no significant change as compared to control animals (Table 1).

In regard to glucose level, insulin level, and HOMA-IR, there was no significant change in their levels in Süßstofftabletten- or vitamin E-treated groups in contrast to control rats (Table 1). 
Table (1): Percentage of body weight change, glucose level, insulin level and HOMA-IR in control, Süßstofftablettenor Süßstofftabletten +vitamin E-treated animals

\begin{tabular}{|l|c|c|c|}
\hline \multicolumn{1}{|c|}{ Groups } & Control & Süßstofftabletten & $\begin{array}{c}\text { Süßstofftabletten } \\
\text { +Vitamin E }\end{array}$ \\
\hline Parameters & & $\mathbf{1} \pm \mathbf{0 . 7} * *$ & $\mathbf{7} \pm \mathbf{0 . 9}$ \\
\hline \% of body weight change & $\mathbf{8 . 6} \pm \mathbf{0 . 5}$ & $\mathbf{- 8 8 \%}$ & $\mathbf{- 1 9 \%}$ \\
\hline Glucose (mg/dl) & & $\mathbf{1 0 6 . 5} \pm \mathbf{0 . 9}$ & $\mathbf{1 0 7 . 3 \pm 0 . 8}$ \\
\hline \% of change from control & & $\mathbf{- 2 \%}$ & $\mathbf{- 2 \%}$ \\
\hline Insulin (mlU/ml) & $\mathbf{0 . 9 7} \pm \mathbf{0 . 0 0 7}$ & $\mathbf{0 . 8 7} \pm \mathbf{0 . 0 4 5}$ & $\mathbf{0 . 8 9} \pm \mathbf{0 . 0 3 7}$ \\
\hline \% of change from control & & $\mathbf{- 1 0 \%}$ & $\mathbf{- 8 \%}$ \\
\hline HOMA-IR & $\mathbf{0 . 2 6} \pm \mathbf{0 . 0 0 3}$ & $\mathbf{0 . 2 2 6} \pm \mathbf{0 . 0 1 5}$ & $\mathbf{0 . 2 3} \pm \mathbf{0 . 0 1 4}$ \\
\hline \% of change from control & & $\mathbf{- 1 3 \%}$ & $\mathbf{- 1 2 \%}$ \\
\hline
\end{tabular}

Values represent mean \pm SE (standard error). (*: $P<0.05, * *: P<0.01$ as compared to control group)

As regards protein profile, animals that received Süßstofftabletten had significant decrease $(p<0.05)$ in serum total protein, albumin and albumin/globulin ratio, while those received vitamin E showed no significant change in protein profile parameters as compared to the corresponding control group (Table 2).

Table (2): Serum total protein, albumin, globulin and albumin/globulin ratio in control, Süßstofftabletten- or Süßstofftabletten + vitamin E-treated animals.

\begin{tabular}{|c|c|c|c|}
\hline $\begin{array}{c}\text { Groups } \\
\text { parameters }\end{array}$ & Control & Süßstofftabletten & $\begin{array}{c}\text { Süßstofftabletten } \\
\text { +Vitamin E }\end{array}$ \\
\hline Total Protein (g/dl) & $6.63 \pm 0.04$ & $5.58 \pm 0.32 *$ & $6.35 \pm 0.13$ \\
\hline$\%$ of change from control & & $-16 \%$ & $-4 \%$ \\
\hline Albumin (g/dl) & $3.43 \pm 0.046$ & $2.44 \pm 0.297 *$ & $3.12 \pm 0.15$ \\
\hline \% of change from control & & $-29 \%$ & $-9 \%$ \\
\hline Globulin (g/dl) & $3.2 \pm 0.028$ & $3.14 \pm 0.045$ & $3.23 \pm 0.032$ \\
\hline \% of change from control & & $-2 \%$ & $1 \%$ \\
\hline Albumin/Globulin & $1.074 \pm 0.02$ & $0.777 \pm 0.087 *$ & $0.965 \pm 0.051$ \\
\hline$\%$ of change from control & & $-28 \%$ & $-10 \%$ \\
\hline
\end{tabular}

Values represent mean \pm SE (standard error). ( $*: P<0.05, * *: P<0.01$ as compared to control group)

In regard to liver functions, ASAT and ALAT activities revealed significant increase $(\mathrm{p}<0.05)$ among Süßstofftabletten group and no significant change among vitamin E-treated group in contrast with control rats (Table $3)$.

Table (3): ASAT and ALAT activities in control, Süßstofftabletten- or Süßstofftabletten +vitamin E-treated animals.

\begin{tabular}{|l|c|c|c|}
\hline \multicolumn{1}{|c|}{$\begin{array}{c}\text { Groups } \\
\text { parameters }\end{array}$} & Sontrol & $\begin{array}{c}\text { Süßstofftablabletten } \\
+ \text { Vitamin E }\end{array}$ \\
\hline ASAT (U/L) & $\mathbf{5 . 8 8} \pm \mathbf{0 . 3}$ & $\mathbf{1 2 6} \pm \mathbf{3 . 1}$ & $\mathbf{1 1 8} \pm \mathbf{1 . 5}$ \\
\hline \% of change from control & & $\mathbf{9 \%}$ & $\mathbf{2 \%}$ \\
\hline ALAT (U/L) & $\mathbf{5 5 . 4 \pm 0 . 1 6}$ & $\mathbf{6 5} \pm \mathbf{2 . 9 6} *$ & $\mathbf{5 8} \pm \mathbf{1 . 1 7}$ \\
\hline \% of change from control & & $\mathbf{1 7 \%}$ & $\mathbf{5 \%}$ \\
\hline
\end{tabular}

Values represent mean \pm SE (standard error). ( $*: P<0.05, * *: P<0.01$ as compared to control group)

Regarding lipid profile, the present results revealed significant decrease $(\mathrm{p}<0.05)$ in total cholesterol, triglycerides and HDL-C accompanied with no significant change in LDL-C, VLDL-C and ratios of TC/HDL-C (risk factor 1) and LDL-C/HDL-C (risk factor 2) in rats received Süßstofftabletten as compared to control group. Meanwhile, there was highly significant decrease $(\mathrm{p}<0.01)$ in total cholesterol, triglycerides and LDL-C, significant 
increase $(\mathrm{p}<0.05)$ in HDL-C, significant decrease $(\mathrm{p}<0.05)$ in risk factors, with no detectable change in VLDL-C in vitamin E-treated rats as compared to control group (Table 4).

Table (4): Changes in total cholesterol (TC), triglyceride (TG), HDL-C, LDL-C, VLDL-C, TC/HDL ratio and LDL/HDL ratio in control, Süßstofftabletten- or Süßstofftabletten +vitamin E-treated animals.

\begin{tabular}{|c|c|c|c|}
\hline $\begin{array}{l}\text { Groups } \\
\text { Parameters }\end{array}$ & Control & Süßstofftabletten & $\begin{array}{c}\text { Süßstofftabletten } \\
\text { +Vitamin E }\end{array}$ \\
\hline Total Cholesterol (mg/dl) & $121.1 \pm 0.38$ & $114 \pm 2.1^{*}$ & $110 \pm 2.5 * *$ \\
\hline$\%$ of change from control & & $-6 \%$ & $-9 \%$ \\
\hline Triglycerides (mg/dl) & $135 \pm 0.7$ & $125 \pm 2.97 *$ & $123 \pm 2.7 * *$ \\
\hline$\%$ of change from control & & $-7 \%$ & $-9 \%$ \\
\hline HDL-C (mg/dl) & $59.4 \pm 0.48$ & $53 \pm 1.87 *$ & $64 \pm 1.5^{*}$ \\
\hline$\%$ of change from control & & $-11 \%$ & $8 \%$ \\
\hline LDL-C (mg/dl) & $34.6 \pm 0.48$ & $36 \pm 1.1$ & $21.4 \pm 1.65 * *$ \\
\hline$\%$ of change from control & & $4 \%$ & $-38 \%$ \\
\hline VLDL (mg/dl) & $27 \pm 0.1$ & $25 \pm 1.3$ & $24.6 \pm 1.5$ \\
\hline$\%$ of change from control & & $-7 \%$ & $-9 \%$ \\
\hline TC/HDL & $2.04 \pm 0.015$ & $2.15 \pm 0.054$ & $1.718 \pm 0.098 *$ \\
\hline$\%$ of change from control & & $5 \%$ & $-16 \%$ \\
\hline LDL/HDL & $0.6 \pm 0.01$ & $0.679 \pm 0.066$ & $0.33 \pm 0.084 *$ \\
\hline$\%$ of change from control & & $13 \%$ & $-45 \%$ \\
\hline
\end{tabular}

Values represent mean \pm SE (standard error). (*: $P<0.05, * *: P<0.01$ as compared to control group)

Concerning kidney functions, serum urea and creatinine showed significant increase $(\mathrm{p}<0.05)$ in Süßstofftabletten group, while there was no detectible change in kidney functions in vitamin E-treated group as compared to control animals (Table 5).

Table (5): Serum urea and creatinine levels in control, Süßstofftabletten- or Süßstofftabletten +vitamin E-treated animals.

\begin{tabular}{|l|c|c|c|}
\hline Groups & Control & Süßstofftabletten & $\begin{array}{c}\text { Süßstofftabletten } \\
\text { +Vitamin E }\end{array}$ \\
\hline Urea (mg/dl) & $37.3 \pm 0.66$ & $45 \pm 2.3 *$ & $39 \pm 1.6$ \\
\hline \% of change from control & & $21 \%$ & $5 \%$ \\
\hline Creatinine (mg/dl) & $1.18 \pm 0.025$ & $1.7 \pm 0.17^{*}$ & $1.3 \pm 0.11$ \\
\hline \% of change from control & & $44 \%$ & $10 \%$ \\
\hline
\end{tabular}

Values represent mean \pm SE (standard error). (*: $P<0.05, * *: P<0.01$ as compared to control group)

In relation to hormones, Süßstofftabletten group revealed significant decrease $(p<0.05)$ in the level of testosterone hormone, but no detectable change was found in its level in vitamin E-treated group as compared to control rats. On the other hand, there was significant increase $(\mathrm{p}<0.05)$ in the levels of both T3 and T4 concentrations in Süßstofftabletten-treated group, but vitamin E ameliorated these effects (Table 6).

Table (6): Serum testosterone, T3 and T4 levels in control, Süßstofftabletten- or Süßstofftabletten +vitamin Etreated animals.

\begin{tabular}{|c|c|c|c|}
\hline $\begin{array}{l}\text { Groups } \\
\text { Parameters }\end{array}$ & Control & Süßstofftabletten & $\begin{array}{c}\text { Süßstofftabletten } \\
\text { +Vitamin E }\end{array}$ \\
\hline Testosterone (ng/dl) & $1.03 \pm 0.004$ & $0.87 \pm 0.048 *$ & $0.98 \pm 0.031$ \\
\hline$\%$ of change from control & & $-16 \%$ & $-5 \%$ \\
\hline T3 (ng/dl) & $47.9 \pm 0.6$ & $55 \pm 2.2^{*}$ & $50 \pm 1.6$ \\
\hline$\%$ of change from control & & $15 \%$ & $4 \%$ \\
\hline T4 ( $\mu \mathrm{g} / \mathrm{dl})$ & $3.036 \pm 0.009$ & $3.7 \pm 0.21 *$ & $3.3 \pm 0.14$ \\
\hline$\%$ of change from control & & $22 \%$ & $9 \%$ \\
\hline
\end{tabular}


Values represent mean $\pm \mathrm{SE}$ (standard error). ( $*: P<0.05, * *: P<0.01$ as compared to control group)

\section{DISCUSSION}

Süßstofftabletten showed highly significant decrease in body weight change. This might be attributed to reduce food consumption per day and may be a consequence to the hypotriglyceridemia and hypocholesterolemic effect caused by sodium saccharin ${ }^{(13)}$. On the other hand, it was observed that vitamin $\mathrm{E}$ has the ability to regain weight loss caused by Süßstofftabletten in male rats. The observed potency of vitamin $\mathrm{E}$ in repairing weight loss gives an indication that $\alpha$-tocopherol is considered as the major lipid soluble antioxidant vitamin protecting membranes and lipoproteins from injury by free radicals. It is suspected also that vitamin $\mathrm{E}$ interact with the hematopoietic growth factors/ committed stem cells, the growth stimulation signaling systems and the various growth factors to stimulate rapid synthesis of blood cells as well as growth and weight increase. The antioxidative and protective roles of vitamin $\mathrm{E}$ may be suggested to be implicated in enhancing weight loss ${ }^{(\mathbf{1 4})}$.

Süßstofftabletten- or vitamin-E treated groups revealed no significant change in serum glucose, insulin level and HOMA-IR. The negative response of Süßstofftabletten in theses parameters may be due to the antagonistic effect of both saccharin and cyclamates, where cyclamate cause increase in glucose and insulin level ${ }^{(\mathbf{1 5})}$, while saccharin decrease them ${ }^{(\mathbf{1 6})}$.

Süßstofftabletten caused significant decrease in protein profile. Yousef $\boldsymbol{e t}$ al. (17) indicated the inhibitory effect of some food additives on the biosynthesis of protein and albumin, which in turn reflects impairment in liver functions ${ }^{(\mathbf{1 6})}$. Furthermore, reductions of protein profile might be due to hepatotoxicity and liver damage that lead to inability of liver to produce proteins and causing utilization of amino acids for the oxidation or gluconeogenesis ${ }^{(18)}$. Vitamin $\mathrm{E}$ ameliorated protein profile, this may be due to the antioxidant activity of vitamin $E$ that repairs the liver and kidney functions to some extent and as a result of this, protein profile also became more enhanced and its level was increased as compared to Süßstofftabletten-treated group. Therefore, the administration of vitamin $\mathrm{E}$ from day one had protective role to liver functions from artificial sweeteners, which is indicated by the significant restoration of serum total protein and albumin.

Süßstofftabletten revealed significant increase in liver functions. The possibility that sodium cyclamate could induce hepatic toxicity, was presented initially by Hagmuller $\boldsymbol{e t} \boldsymbol{a l} .{ }^{(\mathbf{1 8})}$ who observed that animals subjected to sodium cyclamate orally presented alterations such as cellular necrosis and accumulation of glycogen in the cytoplasm of hepatocytes. Also,
Osfor and Elias (19) reported that rats received saccharine for 6 and 12 weeks of administration revealed a significant increase in ALAT activity. ASAT levels were also higher in saccharin-treated rats, in which chronic saccharin intake caused some abnormal changes in metabolic, hormonal and neural responses in male and female rats ${ }^{(20)}$. The elevation in liver enzymes might be resulting from free radicals that interact with cellular membranes or related to breakdown of liver parenchyma. Hepatocellular impairment might be also the main reason for releasing greater than normal levels of intracellular enzymes into the blood (21). Vitamin $\mathrm{E}$ ameliorated liver functions as compared to Süßstofftabletten group. The hepatoprotective effect of vitamin $\mathrm{E}$ might be due to its antioxidant activity ${ }^{(9)}$.

There was significant decrease in total cholesterol, triglycerides and HDL-C in Süßstofftabletten group. This might be due to the effect of saccharin, which cause hypocholesterolemic and hypolipidemic effects ${ }^{\left({ }^{(9)}\right.}$. The total body content of cholesterol depends on the balance between synthesis by the body as well as that absorbed from the diet. The deviation from normal serum cholesterol levels is considered as a symptom of liver diseases ${ }^{(22)}$. The decreased cholesterol level implies liver damage which is in accordance with the increased ASAT and ALAT.

The reduction of cholesterol and triglycerides may be attributed to the suppressed effect of saccharin on liver enzymatic activity of acetyl-CoA synthetase, citrate lyase, and mitochondrial citrate exchange leading to a reduction of available cytoplasmic acetylCoA, which is required for the synthesis of cholesterol and fatty acids (23). Moreover, saccharin analogues have the ability to reduce liver acetyl-CoA carboxylase, phosphatidate phosphohydrolase, and glycerol-3-phosphate acyl transferase activities in a markedly way. Suppression of these enzymes would lead to a reduction of triglyceride synthesis ${ }^{(24)}$.

By using vitamin $\mathrm{E}$, there was a reduction in total cholesterol, triglycerides, LDL-C and risk factors as compared to control rats with an effective amelioration in HDL-C in contrast to Süßstofftabletten-treated group. Vitamin E, due to its solubility in lipids, plays an important role in protecting lipid-rich structure like liver from free radicals damage and an effective inhibitor of autocatalytic process of lipid peroxidation ${ }^{(25)}$. The hypotriglyceridemic effect of vitamin E may be through its effect on increasing the activity of lipase (26). It was observed that vitamin $\mathrm{E}$ decreased cholesterol level and increased HDL-C suggesting that 
vitamin $\mathrm{E}$ could have protective effect on the cardiovascular system ${ }^{(27)}$.

In the present study, there was significant increase in urea and creatinine in rats received Süßstofftabletten. The toxic effects of saccharin on the kidney can lead to disorders in the renal function because of reduction in glomerular filtration rate followed by retention of urea and creatinine in the blood ${ }^{(28)}$. In addition, a study of Singh ${ }^{(29)}$ revealed the ability of saccharin to produce bladder cancer in twogeneration bioassays. Cocarcinogenic and tumorpromoting activities for cyclamate were observed. Cyclamate was incorporated into the bladders of mice (3). By using vitamin $\mathrm{E}$, there was an improvement in kidney functions. Renal amelioration might therefore be due to the antioxidant effect of vitamin $\mathrm{E}$ in neutralizing free radicals. Vitamin E can scavenge free radicals and inhibit the propagation of membrane lipid peroxidation ${ }^{(30)}$.

Süßstofftabletten resulted in low level of testosterone hormone. This may be due to cyclamate, as some intestinal bacteria could desulfonate cyclamate to produce cyclohexylamine, a compound suspected to have some chronic toxicity in animals. Several studies have shown that cyclohexylamine affects the testis of rats. In one study, cyclohexylamine produced testicular atrophy in Dark Agouti (DA) and Wistar rats, but not in mice, at a dietary dose of 400 $\mathrm{mg} / \mathrm{kg}$ per day for up to 13 weeks. The testicular toxicity was not due to the formation of hydroxylated metabolites but to cyclohexylamine. The lack of sensitivity of mouse testis is probably due to the lower tissue concentrations of cyclohexylamine in this species in comparison with rats ${ }^{(31)}$.

On the other hand, using of vitamin E made a great amelioration on testosterone level. Vitamin $\mathrm{E}$ is considered as the basic part of antioxidants in sperm and acts as the important protective against production of reactive oxygen species. Spermatozoa require the ROS for normal functions like acrosome functions, capacitation and fusion of spermatozoa during the processes of fertilizations, but the production of excess amount of ROS induces the lipid peroxidation in membrane of sperm ${ }^{(32)}$. Vitamin E prevents the production of ROS in the sperm membrane during the various motility processes. In addition to scavenging of ROS, this vitamin has the ability to protect the primary reproductive organs and accessory reproductive organs in male. This vitamin functions as anti-sterility function and its shortage results in the degeneration of germinal epithelium occurs. The continuous and small doses of this vitamin lead to improvement of semen characteristics in domestic animals ${ }^{(33)}$.

Süßstofftabletten-treated group revealed significant increase in T3 and T4 levels as compared to control animals. This might be due to the effect of cyclamate, which is bad for the endocrine system as it can cause adenoma of the thyroid gland ${ }^{(34)}$. Also may be due to the alteration in the pituitary - thyroid axis because of the stressing effect of sodium saccharin ${ }^{(16)}$. By using vitamin $E$ there was significant amelioration in thyroidal hormones. Vitamin E appears to exert thyroid protective effects ${ }^{(35)}$.

\section{CONCLUSION}

Finally we found out that the artificial sweeteners are very unhealthy, despite the fact that we consume them every day, and they are present almost in every sweet flavored food. If we would like to live a healthier life, the best solution is using natural sweeteners.

\section{REFERENCES}

1. Chattopadhyay S, Raychaudhuri U, Chakraborty $\mathbf{R}$ (2014): Artificial sweeteners - a review. J Food Sci Technol., 51 (4): 611-621.

2. Martins AT, Santos FS, Scannavino LFL et al. (2010): A. Effect of sodium cyclamate on the rat fetal exocrine pancreas: a karyometric and stereological study. Int. J. Morphol., 28 (3): 899-904.

3. Salminen S, Hallikainen A (2001): Sweeteners. In: Food Additives, $2^{\text {nd }}$ ed., Marcel Dekker, Basel, New Yourk, pp: 447-476.

4. Price JM, Biava CG, Oser BL et al. (1970): Bladder tumors in rats fed cyclohexylamine or high doses of a mixture of cyclamate and saccharin. Science, 167: 11311132.

5. Sanyaolu A, Marinkovic A, Gosse J et al. (2019): Artificial sweeteners and their association with Diabetes: A review. J Pub Health Catalog, 1 (4): 1-3.

6. Abdallah I(2002): Physiological changes induced by long term administration of saccharin compared with aspartame to male albino rats. The Egyptian Journal of Hospital Medicine, 8: 70-81

7. Songthaveesin C, Saikhun J, Kitiyanant $\mathbf{Y}$ et al. (2004): Radio-protective effect of vitamin $\mathrm{E}$ on spermatogenesis in mice exposed to gamma-irradiation: a flow cytometric study. Asian J. Androl., 6: 331-336.

8. Suga T, Watanabe T, Matsumoto Y et al. (1984): Effects of long-term vitamin E deficiency and restoration on rat hepatic peroxisomes. Biochim. Biophys. Acta., 794: 218-224.

9. Al-Attar AM (2011): Vitamin e attenuates liver injury induced by exposure to lead, mercury, cadmium and copper in albino mice. Saudi Journal of Biological Sciences, 18: 395-401.

10. Friedewald WT, Levy RI, Fredrickson DS et al. (1972): Estimation of the concentration of low-density lipoprotein cholesterol in plasma, without use of the preparative ultracentrifuge. Clin.Chem., 18: 499-502.

11. Norbert WT (1995): Clinical guide to laboratory tests. 3rd ed. Saunders W. B., Company, Philadelphia.

12. Rosales-Gómez CA, Martínez-Carrillo BE, ReséndizAlbor AA et al. (2018): Chronic Consumption of Sweeteners and Its Effect on Glycaemia, Cytokines, Hormones, and Lymphocytes of GALT in CD1 Mice. https://doi.org/10.1155/2018/1345282 
13. Amin KA, AlMuzafar HM (2015): Alterations in lipid profile, oxidative stress and hepatic function in rat fed with saccharin and methyl-salicylates. Int $\mathbf{J}$ Clin Exp Med., 8 (4): 6133-6144.

14. Uboh FE, Akpanabiatu MI, Alozie Y et al. (2009): Comparative effect of vitamins $\mathrm{A}$ and $\mathrm{E}$ on gasoline vapours-induced haematotoxicity and weight-loss in male rats. International Journal of Pharmacology, 5 (3): 215221.

15. Kundi H, Butt SA, Hamid S (2015): Variation in the area of islets of langerhans in sodium cyclamate treated rats. Pak Armed Forces Med J., 65 (5): 656-59.

16. Helal EGE, Al-Shamrani A, Abdelaziz MA et al. (2019): Comparison between the effect of sucralose and sodium saccharin on some physiological parameters in male albino rats. The Egyptian Journal of Hospital Medicine, 74 (7): 1552-1558.

17. Yousef MI, Omar SA, El-Guendi MI et al. (2010): Potential protective effects of quercetin and curcumin on paracetamol-induced histological changes, oxidative stress, impaired liver and kidney functions and haematotoxicity in rat. Food Chem. Toxicol., 48: 32463261.

18. Hagmuller $K$, Hellauer $H$, Winkler $R$ et al. (1969): New histological findings and further experimental data on the question of cyclamate tolerance in the guinea pig. Wein. Klin. Wschr., 81: 927.

19. Osfor MMH, Elias TR (2003): Nutritional and biochemical studies on some artificial sweeteners administrated to male albino rats. Bull Nat Res Centre, 28: 377.

20. Andrejić BM, Mijatović VM, Samojlik IN et al. (2013): The influence of chronic intake of saccharin on rat hepatic and pancreatic function and morphology: gender differences. Bosn J Basic Med Sci., 13: 94.

21. Alsoufi MA, Aziz RA, Hussein ZG (2017): Effect of some artificial sweeteners consumption in biochemical parameters of rats. Microbiology and Biotechnology, 5 (3): 1095-1099.

22. Singh RL, Khanna SK, Singh GB (1988): Acute and short term toxicity of a popular blend of yellow and orange II in albino rats. Indian J Exp Biol., 26: 105.

23. Hall IH, Voorstad PJ, Cocolas GH (1983): Antihyperlipidemic activity of saccharin analogues in rodents. J Pharm Sci., 72: 1192.
24. Amin KA, Al-muzafar HM, Abd Elsttar AH (2016): Effect of sweetener and flavoring agent on oxidative indices, liver and kidney function levels in rats. Indian Journal of Experimental Biology, 54: 56-63.

25. Sodhi S, Shamara A, Brar APS et al. (2008): Effect of tocopherol and selenium on antioxidant status, lipid peroxidation and hepatotoxicty induced $\mathrm{Ph}$ ton 264 by Malathion in chicks. Biochemical Physiology, 90: 82-86.

26. Iwata $K$, Inayama $T$, Kato $T$ (1990): Effects of Spirulina platensis on plasma lipoprotein lipase activity in fructose induced hyperlipidemic rats. Journal of Nutritional Science and Vitaminology, 36: 165-171.

27. AL-Harbia MS, El-Shenawya NS, Al-Thomali AW (2013): Protective effect of vitamin $\mathrm{E}$ on mercuric chloride induced hepatic renal functions impairment and oxidative stress in male mice. The Journal of Free Radicals and Antioxidants, 139: 244-264.

28. Turley SD and Dietschy JM (2003): Sterol absorption by the small intestine. Curr Opin Lipidol., 14: 233.

29. Singh Z (2013): Toxicological aspects of saccharin. Food Biology, 2 (1): 04-07.

30. Ghlissi Z, Hakim A, Mnif $H$ et al. (2018): Effect of vitamin $\mathrm{E}$ on reversibility of renal function following discontinuation of colistin in rats: histological and biochemical investigations. Saudi J Kidney Dis Transpl., 29 (1): 10-18.

31. IARC. Monographs on the Evaluation of the Carcinogenic Risk of Chemicals to Humans. Geneva: World Health Organization.

https://toxnet.nlm.nih.gov/cgibin/sis/search/a?dbs+hs db:@term+@DOCNO+918

32. Khan RU, Rahman ZU, Javed I et al. (2012): Effects of vitamins, probiotics and protein level on semen traits and some seminal plasma macro and micro minerals of male broiler breeders after zinc-induced molting. Biol Trace Elem Res., 148: 44-52.

33. Zubair M (2017): Effects of dietary vitamin E on male reproductive system. Asian Pacific Journal of Reproduction, 6 (4): 145-150.

34. https://www.naturalpedia.com/cyclamate-sourceshealth-risks.html

35. https://www.livestrong.com/article/502167-the-effectof-vitamin-e-on-the-thyroid/ 